\section{Vertical alveolar crest split and widening - an experimental study on cow ribs, ultrasonic tool development and test on human cadaver heads}

\author{
Angelo Troedhan, ${ }^{1}$ Andreas Kurrek, ${ }^{2}$ \\ Marcel Wainwright ${ }^{3}$ \\ ${ }^{1}$ Center for Facial Esthetics Vienna, \\ Vienna, Austria; 'Implantology Clinic \\ Ratingen, Ratingen, Germany; \\ ${ }^{3}$ Implantology Clinic Kaiserswerth, \\ Düsseldorf, Germany
}

\section{Abstract}

Vertical alveolar crest splitting and horizontal distraction of narrow alveolar crests is limited when rotating and low frequency oscillating tools are used due to large amounts of procedural bone loss and poor handling provisions. Aim of this study was to determine the safest osteotomy depth and to develop ultrasonic-surgery-tips to enable flapless vertical crest splitting and distraction of narrow alveolar crests of $2 \mathrm{~mm}$ or less. The safest osteotomy depth was determined on a cow-rib-model. To enable a flapless crest splitting and widening procedure, prototype-tips for the Piezotome-device were developed and tested against mechanical tools (widening screws and distractors) on cow-ribs, as well as their safe use in the hands of novicesurgeons on human cadaver heads. A minimum vertical osteotomy depth of 7-8 mm revealed the least fracture rates (3\%). The use of the ultrasonic distraction tools showed the least risk of procedural failures (2\%). Twentythree Piezotome-trainees performed the procedure with the developed tips on fresh full human cadaver skulls with a success rate of $100 \%$. The results of this study suggest that, with the use of ultrasonic surgical devices, the indication for vertical crest-splitting can be narrowed down to a crest width of $2 \mathrm{~mm}$ and even less and that it can be performed flapless, thus leaving the physiological bone-periosteum system fully intact.

\section{Introduction}

Lateral bone loss of the alveolar crest, narrowing and deformities occur for various reasons: as a result of trauma, periodontal disease, surgical treatment or congenital partial anodontia. Alveolar crest resorption after tooth loss and long time wearing of removable partial or full prosthesis has been shown to follow a certain pattern: the buccal side of the alveolar crest is primarily resorbed, which first reduces its width and only later its height. .,2,3 $^{1,2}$

Although immediate reconstruction of the extraction socket (socket preservation) ${ }^{4}$ or immediate implant insertion ${ }^{5}$ could preserve a satisfactory width of the alveolar crest, these procedures are still rarely performed by the general dentist.

Various surgical techniques were published to regain satisfactory alveolar crest width both in the upper and the lower jaw, such as lateral appositional bone grafts, ${ }^{6}$ various membrane techniques $^{7}$ in connection with or without autologous or synthetic bone grafts ${ }^{8,9,10}$ or by means of alveolar distraction osteogenesis. ${ }^{11}$ These require expensive equipment as well as high skills by the surgeon and compliance on the patient's side and are still leading to considerable donor site complications, ${ }^{12,13}$ especially when great amounts of bone have to be harvested. As a side-effect, the preparation at the augmentation site causes additional procedural bone loss.

The less traumatic alveolar ridge expansion to widen the alveolar crest sufficiently was introduced in the early $90 s^{14}$ and excellent results have been achieved especially in the maxillary narrow alveolar crest, ${ }^{15-20}$ but also in the posterior mandible ${ }^{21,22}$ or both. ${ }^{23,24}$

Several osteotomy-tools were developed for vertical alveolar crest splitting and alveolar ridge expansion, mainly for the more spongious, and thus more easy to widen maxillary narrow alveolar ridge (e.g. alternating osteotomes with variable conicity: Bontempi Medizintechnik GmbH, Tuttlingen, Germany; Q-Tom: Trinon Titanium GmbH, Karlsruhe, Germany), but recently also for the more difficult expansion of the almost pure cortical bone of the narrow mandibular alveolar ridge (e.g. Split-Control, Crest-Control: Hager \& Meisinger GmbH, Neuss, Germany). Due to the anatomical and surgical approach situation in the patients oral cavity (especially distal regions), these instruments do not allow a perfect and precise vertical osteotomy to the necessary depth and cause bone loss by themselves, thus limiting the application to remaining alveolar crest widths of $3 \mathrm{~mm}$ minimum.

A further enhancement and applicability of the vertical alveolar crest split to narrow alveolar crests of less than $2 \mathrm{~mm}$ was achieved by the use of ultrasonic surgical devices ${ }^{25,26}$ since it follows the principles of natural fracture healing. ${ }^{27-29}$ Nevertheless, the authors still describe the surgical protocol with a vast full thickness mucoperiostal flap and periostal detachment from the entire buccal cortical bone, thus interrupting the nutrition of the alveolar crest which might lead to secondary procedural resorption, healing delays and complications in case the distracted buccal cortical bone fractures at the baseline leave the sur-
Correspondence: Angelo Troedhan, Center for Facial Esthetics Vienna, Brauhausgasse 12-14, A-1050 Vienna, Austria.

Tel. +43.1.5449128 - Mobile: +43.664 .5009246 .

Fax: +43.1.544912821

E-mail: troed@aon.at

Key words: Piezotome surgery, jaw-bone-management, flapless alveolar crest widening.

Contributions: all authors contributed equally.

Conflict of interests: the authors declare that their research was supported by Satelec-ACTEON France which manufactured prototypes according to the author's design-templates and the optimization process throughout the experimental studies.

Acknowledgments: we gratefully thank SatelecACTEON France for their contribution to manufacture prototypes for the current study and optimize them concerning oscillation behaviour.

Received for publication: 14 June 2012.

Revision received: 4 September 2012.

Accepted for publication: 12 November 2012.

This work is licensed under a Creative Commons Attribution NonCommercial 3.0 License (CC BYNC 3.0).

(C) Copyright A. Troedhan et al., 2012

Licensee PAGEPress, Italy

Surgical Techniques Development 2012; 2:e10 doi:10.4081/std.2012.e10

geon in a situation comparable to a free autologous bone graft procedure.

The aim of the present study was: i) to evaluate the safety parameters for vertical alveolar crest splitting, especially for the narrow mandibular alveolar crest based on the average anatomy of endentolous mandibles ${ }^{30,31}$ and the author's panoramic X-ray survey over their own patient clients; and ii) to develop highly fail-safe ultrasonic surgical tools also for the widening process in order to allow the surgeon a safe procedure without having to prepare a full thickness mucoperiostal flap and without uncontrollable procedural bone fractures, loss or devitalization in the augmentation site to achieve lesser post surgical patient's morbidity and bone loss in the healing period comparable to flapless dental implant insertion. ${ }^{32-34}$

\section{Materials and Methods}

To establish a realistic research-protocol and base for further praxis-oriented developments of surgical tools and protocols, approximately 600 panoramic X-rays of patients not eligible for implants in the premolar and molar mandible region due to narrow alveolar crests 
of less than $3 \mathrm{~mm}$ were scanned by the authors (approx. 200 each) out of their routine patientclients in their offices. These revealed an average bone height above the mandible nerve of 10 to $12 \mathrm{~mm}$. Only $5 \%$ of the scanned X-rays showed a bone height of less than $10 \mathrm{~mm}$ above the mandible nerve. Thus, the depth limit for vertical alveolar crest osteotomies was determined with $8 \mathrm{~mm}$ to provide an applicability in $95 \%$ of cases in the daily oral surgeon's routine and was taken as the uppermost limit for the osteotomy depth in the experiments.

Fresh cow ribs of adult milk-cows with intact periosteum were taken. Being histologicallywoven bone formations, they resembled an accepted experimental model for the posterior mandible. ${ }^{35-37}$ They were selected in size and length to resemble the average human lateral atrophic posterior mandible and were cut to 180 pieces with $60 \mathrm{~mm}$ length and stored at $4^{\circ} \mathrm{C}$ at $100 \%$ humidity (Figure 1 ). The prepared 180 specimens were then separated into 6 groups with 30 specimens each.

Subsequently, each piece was warmed up to $32{ }^{\circ} \mathrm{C}$ in $100 \%$ humidity, which resembles the inner temperature of the jawbone in the human mandible during oral surgical procedures.

With the ultrasonic surgical device Piezotome II (60 W/28-36 KHz; SatelecACTEON, Merignac, France; Figure 2) and the BS5-tip (bone scalpel; Satelec-ACTEON, Merignac, France; Figure 3), vertical osteotomies in a mesiodistal length of $35 \mathrm{~mm}$ were performed on each specimen (Figure 4): group A (30 specs), $3 \mathrm{~mm}$ osteotomy depth group B (30 specs), $4 \mathrm{~mm}$ osteotomy depth; group C (30 specs), $5 \mathrm{~mm}$ osteotomy depth; group D (30 specs), $6 \mathrm{~mm}$ osteotomy depth; group E (30 specs), $7 \mathrm{~mm}$ osteotomy depth; group F (30 specs), $8 \mathrm{~mm}$ osteotomy depth.

Both at the beginning and at the end of the $35 \mathrm{~mm}$ longitudinal vertical osteotomy line, $90^{\circ}$ relief osteotomies to one side - presumed as the buccal side - were performed with the LC1-tip (Ligament cutter; Piezotome; Figure 5) in a straight downward movement to the corresponding osteotomy depth to resemble a realistic surgical situation without a mucoperiostal flap leaving the periosteum completely uncut and fully attached to the buccal cortical bone of the alveolar ridge (Figure 6).

The widening process in this first experimental series of different vertical osteotomy depths of 3 to $8 \mathrm{~mm}$ was performed with the Horizontal Spreader-device from Hager \& Meisinger GmbH (Crest Control) to achieve a widening gap of $4 \mathrm{~mm}$ which is sufficient for most implant systems and stays within the biological margins of safe fracture healing..$^{27-29}$

Additionally, the widening angle was analysed in group B with a $4 \mathrm{~mm}$ vertical osteotomy (Figure 7) and group F with an 8 $\mathrm{mm}$ vertical osteotomy (Figure 8), both widened up to an osteotomy gap of $4 \mathrm{~mm}$.

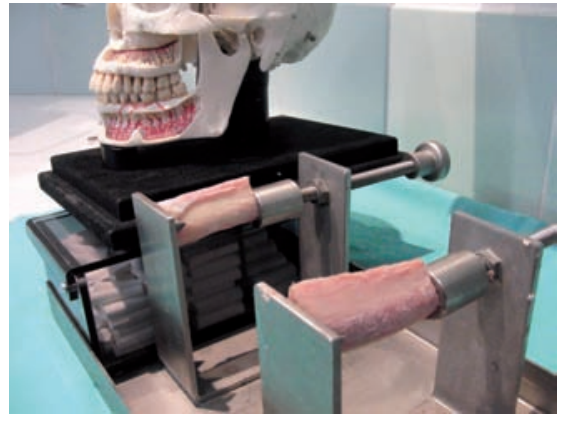

Figure 1. Experimental setup with fresh cow ribs (dimension comparison to the human lateral mandible).

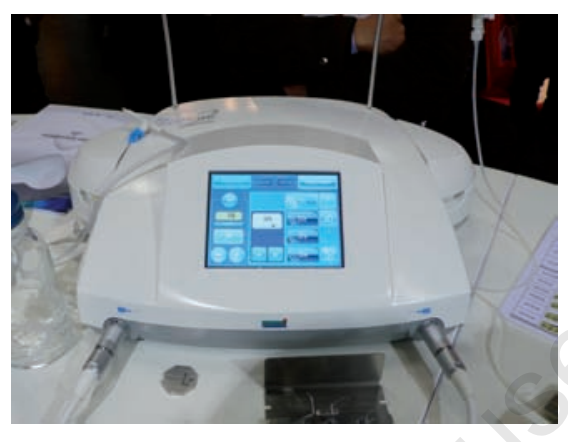

Figure 2. Ultrasonic surgical device Piezotome II (Satelec-ACTEON, Merignac, France).

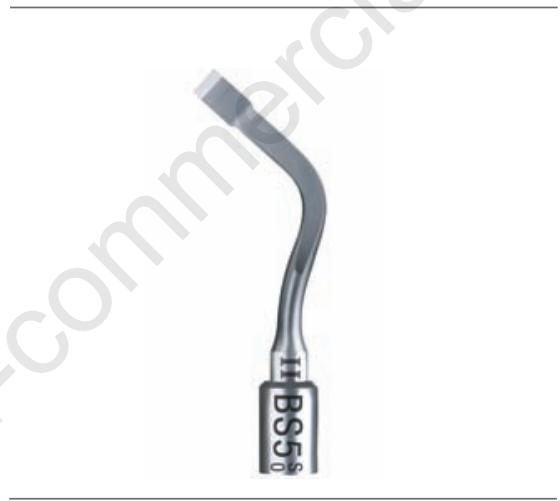

Figure 3. Bone Scalpel BS5 (Piezotome I/II/SOLO; Satelec-ACTEON).

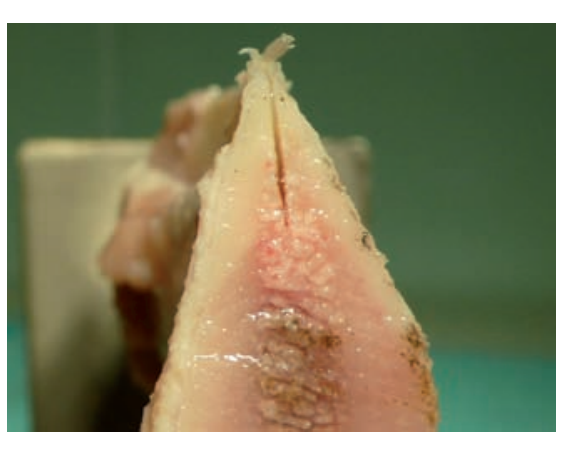

Figure 4. Vertical osteotomy performed with Bone Scalpel BS 5.

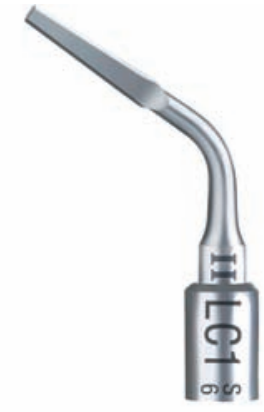

Figure 5. Ligament cutter LC1 (Piezotome I/II/SOLO; Satelec-ACTEON/France) used as a bone scalpel.

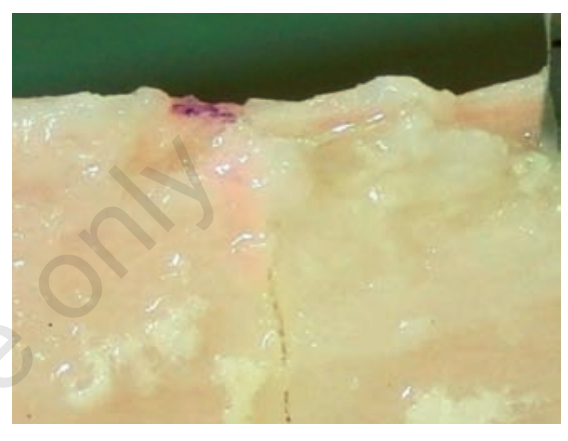

Figure 6. Lossless buccal relief-osteotomy performed with LC1 from the inside to the outside.

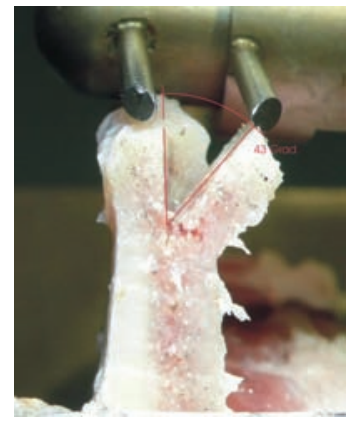

Figure 7. Mean widening angle at $4 \mathrm{~mm}$ osteotomy depth and $4 \mathrm{~mm}$ widening gap. Cracks at the baseline can be detected.

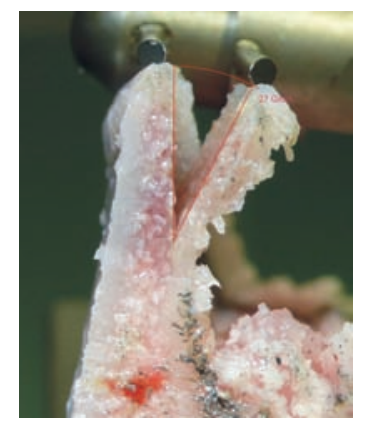

Figure 8. Mean widening angle at $8 \mathrm{~mm}$ osteotomy depth and $4 \mathrm{~mm}$ widening gap. No cracks at the baseline can be detected. 
All fractures occurring at the baseline of the distracted compacta-lamella were noted as a failure to the study protocol with 1 for later statistical analysis. A lack of a fracture was noted as 0 .

After statistical evaluation of the safest osteotomy depth causing the least fractures at the baseline of the distracted bone lamella, the authors (TKW-Research-Group) calculated and designed specific ultrasonic tips for the vertical osteotomy- and widening procedure in computer models and asked Satelec-ACTEON France to machine prototypes according to the author's design-templates (Figure 9).

After having received the prototype-set of ultrasonic crest splitters and wideners designed by the authors (TKW-Research-Group) and manufactured by Satelec-ACTEON/France, another set of 150 cow-rib pieces of the same dimensions and conditions as in the first part of the experiment was prepared.

The first and thinnest of the ultrasonic prototype tips (TKW-CS1) was used to perform the initial vertical longitudinal osteotomy in a length of $35 \mathrm{~mm}$ and depth of $8 \mathrm{~mm}$ on all 150 specimens, followed by the $90^{\circ}$ relief osteotomies of the buccal compacta lamella at both ends of the longitudinal (mesio-distal) vertical osteotomy with TKW-CS3 (Figures 6 and 9).

The 150 specimens treated with the TKWCS1 and TKW-CS3 ultrasonic tips with a $8 \mathrm{~mm}$ deep vertical osteotomy were then separated into three groups of 50 specimens each to perform the expansion process to a 4 mm-gap with different tools: group I (50 specs), widening to a $4 \mathrm{~mm}$ gap with the Split Control-Screws (Hager \& Meisinger); group II (50 specs): widening to a $4 \mathrm{~mm}$ gap with the Horizontal Spreader (Hager \& Meisinger); group III (50 specs), widening to a $4 \mathrm{~mm}$ gap with the TKW-ultrasonic-Crest-Widener CS2-4-5-6 (TKW-ResearchGroup \& Satelec-ACTEON) (Figures 10-15).

Stress-cracks and additional fractures observed in the distracted bone plate were recorded as failure (1) to the study protocol and analysed statistically to determine the safety of the ultrasonic widening tips in comparison to the traditional widening devices of group I and II.

Statistical analysis included determination of mean value, standard deviation (SD), variance analysis, T-test, T-test derived significance in percent and P-value determination (Tables 1, 2, and 3).

Q2-implants (12 mm length/4,5 mm diameter; TRINON Titanium $\mathrm{GmbH}$ ) were inserted to simulate a simultaneous implant insertion (Figure 16).

After setting up the final flapless crest splitting surgical protocol according to the results of group III, the prototype-tips were tested on 12 fresh and non-formaldehyd-treated human cadaver heads by 23 ultrasound surgery trainees on 25 sites, both in the maxillary and mandibular narrow alveolar crest, during a

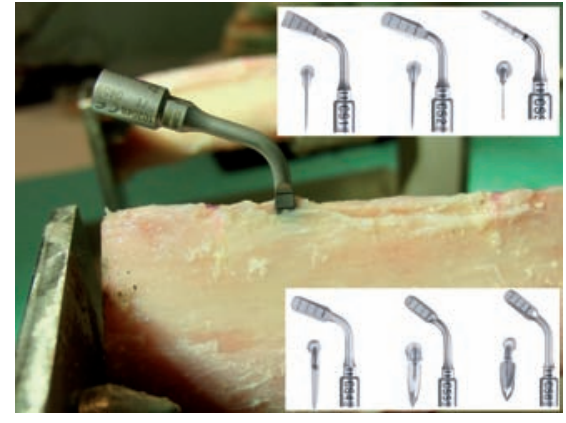

Figure 9. Lossless mesio-distal vertical osteotomy performed with TKW-Crest Splitter 1 to $8 \mathrm{~mm}$ osteotomy depth, buccal relief osteotomy performed with CS3 and basic design of the ultrasonic working tips TKW-CS1-6.

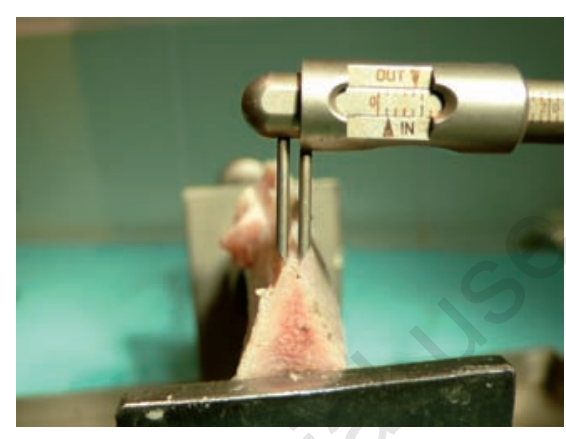

Figure 10. Experimental setup for TKWCS-Tips testing with selected cow-rib's crest-widths of 1 to $1.5 \mathrm{~mm}$.

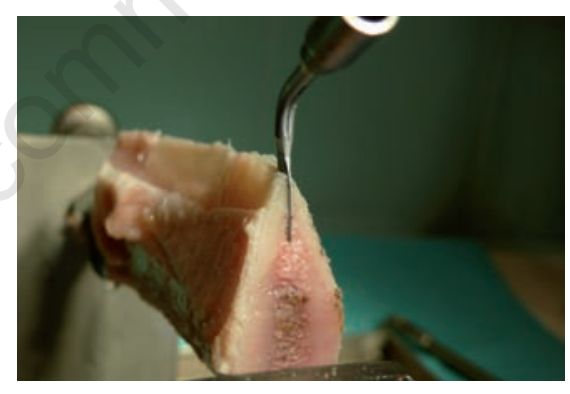

Figure 11. Cutting profile of the ultrasonic TKW-CS1 tip (lossless bone cut).

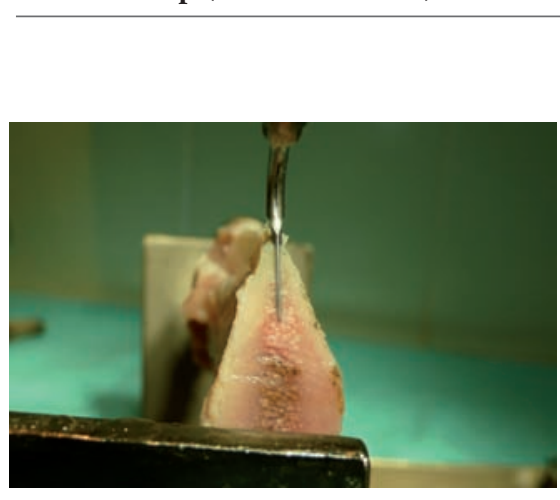

Figure 12. Initial widening of the osteotomy with ultrasonic TKW-CS2 tip.

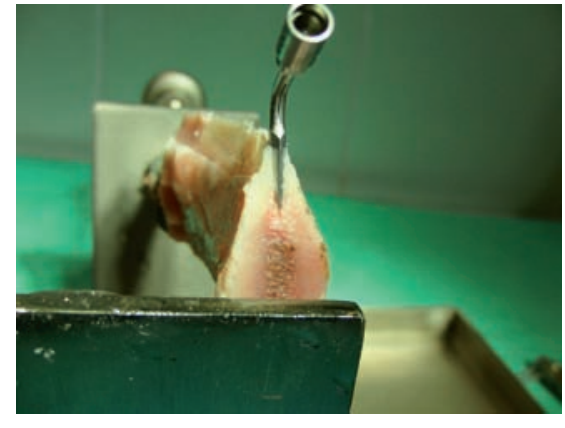

Figure 13. Step-by-step widening procedure after buccal relief osteotomy with TKWCS3. The ultrasonic TKW-CS4 tip widens the top of the alveolar crest to $2 \mathrm{~mm}$.

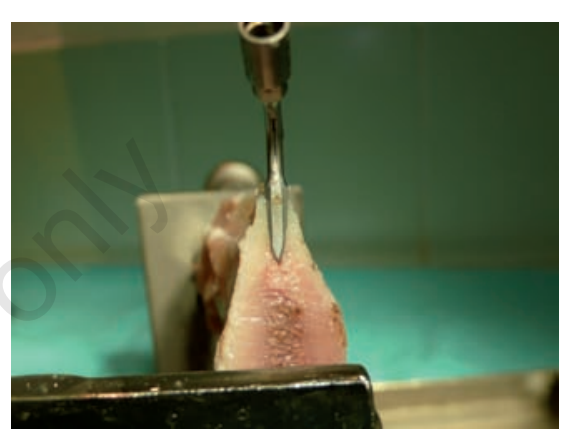

Figure 14. Profile of the widening procedure with ultrasonic TKW-CS5 tip.

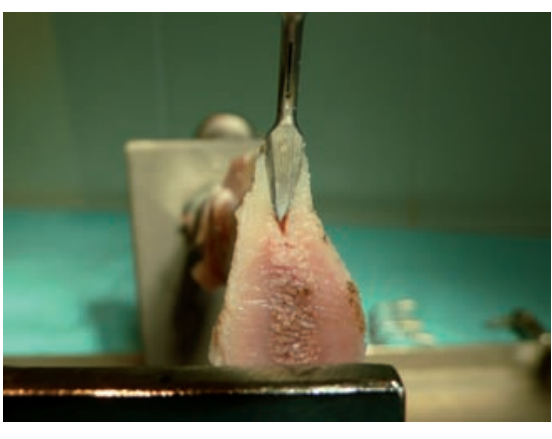

Figure 15. Final widening with ultrasonic TKW-CS6 tip. Resulting gap is now $4 \mathrm{~mm}$ on top of the alveolar crest.

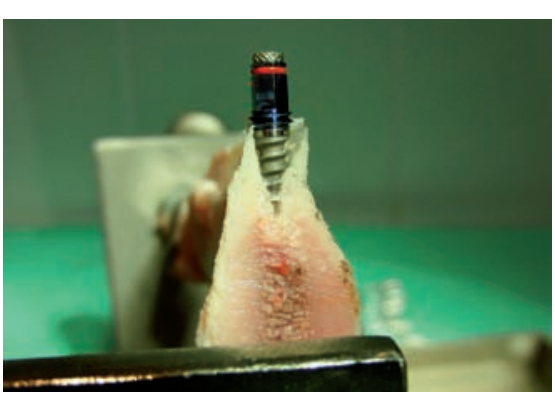

Figure 16. Primarily stable insertion of a 12 mm length/4.5 mm diameter Q2-implant (Trinon Titanium GmbH). Inserted implants also act as doorbolders to keep the achieved widening stable against the closing elasticity of the bone. 
Piezotome-surgery hands-on-course at the Institute for Anatomy of the Medical University Vienna.

Crest width was measured between 1.5 to 3 mm prior to surgery after a single mesio-distal top-crestal mucoperiostal incision. The trainees had to perform a flapless vertical alveolar crest split of $8 \mathrm{~mm}$ depth and $10 \mathrm{~mm}$ minimum of length, a widening to $4 \mathrm{~mm}$ and machine-aided insertion of 1 or 2 Q2-Implants of $12 \mathrm{~mm}$ length and $4.5 \mathrm{~mm}$ diameter primarily stable with the implant motor of the Implant Center (Satelec-ACTEON/France) with an insertion torque of minimum $30 \mathrm{Ncm}$, without clinically detectable fractures of the baseline of the distracted buccal compacta to simulate a real-patient-surgery. After the surgery and a check by the authors, the mucoperiosteum of the surgical site was removed and checked for hidden fractures.

\section{Results}

While at an osteotomy depth of $3 \mathrm{~mm}$ baseline fractures of the distracted compacta lamella occur in $77 \%$ cases, the occurrence of these fractures decreases significantly with deeper osteotomy depths to only $3 \%$ when the vertical cut is at $8 \mathrm{~mm}$ in the simulated setup of a vertical crest splitting and horizontal widening procedure with a resulting $4 \mathrm{~mm}$ gap in the mandible (Table 1).

Furthermore, Figure 17 shows that the highest decrease of a fracture occurance takes place between an osteotomy depth of 6-7 $\mathrm{mm}$ (7\%) and it is lowest at $8 \mathrm{~mm}(3 \%)$.

This fact is also related to the widening angle of the expanded buccal compacta lamella at a top-crestal widening gap of $4 \mathrm{~mm}$ measured from the base-line-hinge, which is $44.5^{\circ}$ at $4 \mathrm{~mm}$ vertical osteotomy and $27.2^{\circ}$ at an osteotomy depth of $8 \mathrm{~mm}$ (Table 2).

Once the optimum osteotomy depth was statistically determined with 7 to $8 \mathrm{~mm}$ osteotomy depth, the different tools for the horizontal widening process were compared at this osteotomy depth of $8 \mathrm{~mm}$ and resulted in a failure rate (fracture of the base-line-hinge) of $35 \%$ when tools such as non-cutting-wideningscrews like Split Control were used (Table 3). The fracture rate of the baseline of the distracted buccal compacta lamella decreased to $18 \%$ when instruments like Crest Control were used (Table 3). The least fracture rate of the baseline of only $2 \%$ was achieved with the use of the prototypes for ultrasound enhanced alveolar crest widening (Table 3 ).

In the real-patient-surgery simulation on the cadaver heads, all 23 trainees succeeded to insert Q2-implants machine-aided in 25 vertical-crest-splitting surgical sites primarily stable with a minimum insertion torque of 30
Table 1. Baseline fractures at different vertical cuts.

\begin{tabular}{|c|c|c|c|c|c|c|}
\hline $\begin{array}{l}\text { Ribs } \\
\text { ( } 30 \text { specs)/ } \\
\text { widening } \\
\text { to } 4 \mathrm{~mm}\end{array}$ & $\begin{array}{l}\text { Vertical } \\
\text { cut } 3 \mathrm{~mm} \\
\text { Group A }\end{array}$ & $\begin{array}{l}\text { Vertical } \\
\text { cut } 4 \mathrm{~mm} \\
\text { Group B }\end{array}$ & $\begin{array}{l}\text { Vertical } \\
\text { cut } 5 \mathrm{~mm} \\
\text { Group C }\end{array}$ & $\begin{array}{l}\text { Vertical } \\
\text { cut } 6 \mathrm{~mm} \\
\text { Group D }\end{array}$ & $\begin{array}{l}\text { Vertical } \\
\text { cut } 7 \mathrm{~mm} \\
\text { Group E }\end{array}$ & $\begin{array}{l}\text { Vertical } \\
\text { cut } 8 \mathrm{~mm} \\
\text { Group F }\end{array}$ \\
\hline Mean value (\%) & 77 & 70 & 47 & 40 & 7 & 3 \\
\hline SD & 00.42 & 00.46 & 00.49 & 00.49 & 00.25 & 00.18 \\
\hline Variance & 00.18 & 00.22 & 00.26 & 00.25 & 00.06 & 00.03 \\
\hline Significance & & $\begin{array}{c}\text { Compared } \\
\text { to } 3 \mathrm{~mm}: \\
- \\
(\mathrm{P}<0.56)\end{array}$ & $\begin{array}{c}\text { Compared } \\
\text { to } 4 \mathrm{~mm}: \\
- \\
(\mathrm{P}<0.08)\end{array}$ & $\begin{array}{c}\text { Compared } \\
\text { to } 5 \mathrm{~mm} \text { : } \\
- \\
(\mathrm{P}<0.60)\end{array}$ & $\begin{array}{c}\text { Compared } \\
\text { to } 6 \mathrm{~mm}: \\
* * * \\
(\mathrm{P}>0.002)\end{array}$ & $\begin{array}{c}\text { Compared } \\
\text { to } 7 \mathrm{~mm}: \\
- \\
(\mathrm{P}<0.56) \text {; } \\
\text { Compared } \\
\text { to } 5 \mathrm{~mm} \text { : } \\
* * * \\
(\mathrm{P}>0.001)\end{array}$ \\
\hline
\end{tabular}

***, significance at the 0.002 level; ${ }^{* * *}$, significance at the 0.001 level. Specs, specimens; SD, standard deviation.

Table 2. Widening angle of the expanded buccal compacta lamella at different vertical cuts.

\begin{tabular}{lcc} 
Ribs (30 specs) & $\begin{array}{c}\text { Vertical cut } 4 \\
\text { mm/widening angle at } \\
\text { Group B }\end{array}$ & $\begin{array}{c}\text { Vertical cut } 8 \\
\text { mm/widening angle at } 4 \mathrm{~mm} \\
\text { Group F }\end{array}$ \\
Mean value $\left(^{\circ}\right)$ & 44.05 .00 & 27.02 .00 \\
SD $\left(^{\circ}\right)$ & 01.05 & 01.02 \\
\hline Variance $\left(^{\circ}\right)$ & 02.05 & 01.07 \\
Significance & $* * *$ & Compared to group B: $(\mathrm{P}>0.001)$ \\
\hline$*^{* * *}$, significance at the 0.001 level. Specs, specimens; SD, standard deviation. &
\end{tabular}

Table 3. Fracture rates in groups I, II, and III.

\begin{tabular}{|c|c|c|c|}
\hline & Group I & Group II & Group III \\
\hline $\begin{array}{l}\text { Ribs ( } 50 \text { specs)/ } \\
\text { Vertical cut } 8 \mathrm{~mm}\end{array}$ & $\begin{array}{l}\text { Widening to } 4 \mathrm{~mm} \\
\text { with Split Control } \\
\text { (Hager \& Meisinger) }\end{array}$ & $\begin{array}{l}\text { Widening to } 4 \mathrm{~mm} \\
\text { with Crest Control } \\
\text { (Hager \& Meisinger) }\end{array}$ & $\begin{array}{l}\text { Widening to } 4 \mathrm{~mm} \\
\text { with TKW-CS4-6 } \\
\text { (TKW/Acteon) }\end{array}$ \\
\hline Mean value (\%) & 35 & 18 & 2 \\
\hline SD & 00.48 & 00.38 & 00.14 \\
\hline Variance & 00.23 & 00.15 & 00.02 \\
\hline Significance & - & $\begin{array}{l}\text { Group I compared } \\
\text { to Group II: * } \\
\quad(P>0.05)\end{array}$ & $\begin{array}{l}\text { Group I compared } \\
\text { to Group III: } * * * \\
\text { (P>0.001) } \\
\text { Group II compared } \\
\text { to Group III: } * * \\
\text { (P>0.01) }\end{array}$ \\
\hline
\end{tabular}

*, significance at the 0.05 level; $* *$, significance at the 0.01 level; ${ }^{* * *}$, significance at the 0.001 level. Specs, specimens; SD, standard deviation.

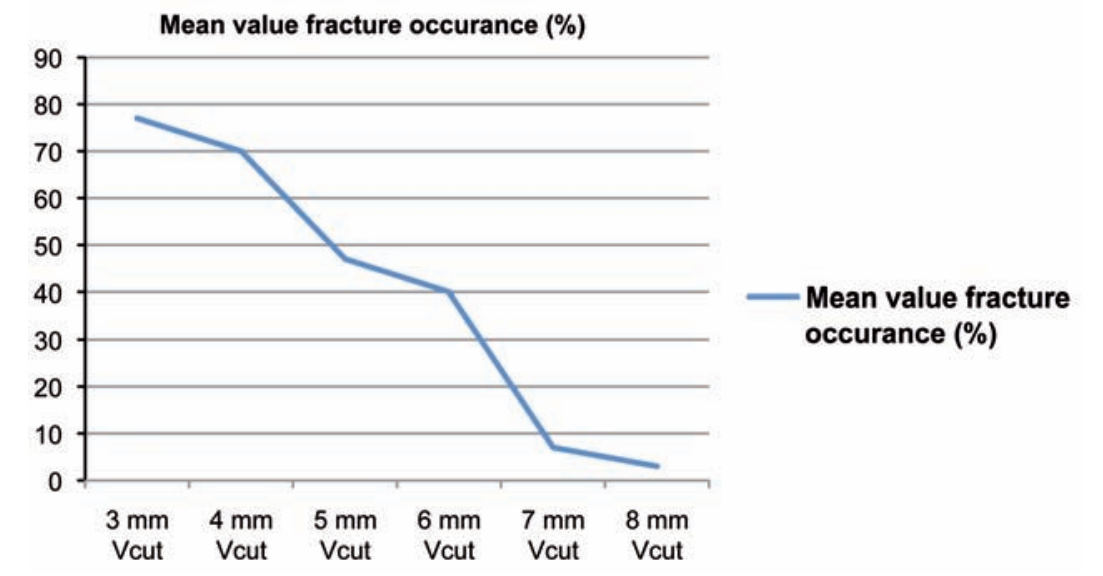

Figure 17. Mean value comparison graph: at $7 \mathrm{~mm}$ the baseline-fracture occurrence decreases significantly from $40 \%$ at $6 \mathrm{~mm}$ to less than $10 \%$ at $7 \mathrm{~mm}$. 
$\mathrm{Ncm}$. The later inspection of the baseline of the buccal lamella after resection of the mucoperiosteum revealed no single fracture of the baseline (Failure rate $0 \%$ ).

\section{Discussion}

Following the philosophy of an undisturbed and undelayed utilization of physiological bone repair mechanisms patient-friendly surgical procedures in bone augmentation should possibly be least traumatic. This could be achieved when the surgeon has to deal with only vital bone or even more with vital bone not detached from the nurturing periosteum by leaving physiological systems intact and minimizing unintended procedural iatrogenic lesions to the surgical site by too coarse tools.

To achieve this target in vertical alveolar crest splitting and widening to an implant-relevant width of a $4 \mathrm{~mm}$ gap also at remaining crest widths of only $1 \mathrm{~mm}$, a minimum vertical osteotomy depth of 7-8 $\mathrm{mm}$ is necessary, as suggested by this study, in order to prevent the risk of an uncontrolled fracture of the baseline of the distracted buccal lamella. To further prevent uncontrolled fractures of the expanded bone section, mesial and distal buccal relief osteotomies are mandatory.

For the widening process after the vertical osteotomy, non-cutting widening screws do show a higher rate of unintended fractures than instruments that distribute the distracting forces over a wider area of the distracted compacta.

Screws apply distracting peak forces on a small area of the distracted compacta, thus causing uncontrolled vertical and baseline fractures to a considerable degree. Flat transport-plates distractor-designs distribute the distracting forces over a much wider bone area, thus bearing a significant lesser risk of uncontrolled fractures.

Ultrasonic oscillating wideners, such as the newly developed TKW-Crest-Splitters and Wideners achieve the best distracting force distribution over a wide area of the distracted compacta-bone additionally enhanced by the ultrasonic cavitation effect, resulting in the least risk of uncontrolled fractures and thus possible devitalization of the distracted bone, as the results of this study suggest.

Furthermore, ultrasonic surgical devices enable the oral surgeon to split a narrow alveolar crest of $2 \mathrm{~mm}$ or less with ultimate precision and ease, since rotating and low frequency oscillating instruments cause a significant procedural bone loss due to instrument dimension and/or difficulties in taming the cutting instrument.

Last but not least, the study with the first time Piezotome-users has shown that even untrained oral surgeons are able to perform a flapless crest-splitting procedure according to the established protocol and application-tips with ease and without failure.

First hand experiences in patient-treatment with this protocol and ultrasonic tip-set approve the results of this study. Comparable to flapless dental implant insertion, the Piezotome-enhanced flapless vertical alveolar crest split and widening could lower patient's post-surgical morbidity regarding pain and swelling and might reduce bone resorption in the healing period, which is currently investigated in a clinical multicentre study.

\section{References}

1. Drago CJ. Rates of osseointegration of dental implants with regard to anatomical location. J Prosthodont 1992;1:29-31.

2. Cawood JI, Howell RA. A classification of the edentulous jaws. Int J Oral Max Surg 1988;17:232-6.

3. Ulm C, Solar P, Blahour R, et al. Reduction of the compact and cancellous bone substances of the edentulous mandible caused by resorption. Oral Surg Oral Med 0 1992;74:131-6.

4. Suhonen JT, Meyer BJ. Polylactic acid (PLA) root replica in ridge maintenance after loss of a vertically fractured incisor. Endod Dent Traumatol 1996;12:155-60.

5. Wiesen M, Kitzis R. Preservation of the alveolar ridge at implant sites. Periodontal Clin Investig 1998;20:17-20.

6. Marx RE. Clinical application of bone biology to mandibular and maxillary reconstruction. Clin Plast Surg 1994;21:377-92.

7. Buser D, Dula K, Lang NP, et al. Long-term stability of osseointegrated implants in bone regenerated with the membrane technique. Five-year results of a prospective study with 12 implants. Clin Oral Implan Res 1996;7:175-83.

8. Burchardt H. The biology of bone graft repair. Clin Orthop Relat Res 1983;174:2842.

9. Schmid J, Hämmerle $\mathrm{CH}$, Flückiger L, et al. Blood-filled spaces with and without filler materials in guided bone regeneration. A comparative experimental study in the rabbit using bioresorbable membranes. Clin Oral Implan Res 1997;8:75-81.

10. Von Arx T, Buser D. Horizontal ridge augmentation using autogenous block grafts and the guided bone regeneration technique with collagen membranes: a clinical study with 42 patients. Clin Oral Implan Res 2006;17:359-66.

11. Sant S, Jagtap A. Alveolar distraction osteogenesis: revive and restore the native bone. J Prosthodont 2009;18:694-7.
12. Pape HC, Evans A, Kobbe P. Autologous bone graft: properties and techniques. J Orthop Trauma 2010;24:36-40.

13. Finkemeier CG. Current concepts review: bone-grafting and bone-graft substitutes. J Bone Joint Surg 2002;84:454-64.

14. Summers RB. The osteotome technique. 2. The ridge expansion osteotomy (RE0) procedure. Compendium 1994;15:422-6.

15. Simion M, Baldoni M, Zaffe D. Jawbone enlargement using immediate implant placement associated with a split-crest technique and guided tissue regeneration. Int J Periodont Rest 1992;12:462-73.

16. Scipioni A, Bruschi GB, Calesini G. The edentulous ridge expansion technique: a five-year study. Int J Periodontics Rest 1994;14:451-9.

17. Sethi A, Kaus T. Maxillary ridge expansion with simultaneous implant placement: 5year results of an ongoing clinical study. Int J Oral Max Impl 2000;15:491-9.

18. Ferrigno N, Laureti M. Surgical advantages with ITI TE implants placement in conjunction with split crest technique. 18month results of an ongoing prospective study. Clin Oral Implan Res 2005;16:14755.

19. Chiapasco M, Ferrini F, Casentini P, et al. Dental implants placed in expanded narrow edentulous ridges with the Extension Crest device. A 1-3-year multicenter follow-up study. Clin Oral ImplanRes 2006;17:265-72.

20. Elian N, Jalbout Z, Ehrlich B, et al. A twostage full-arch ridge expansion technique: review of the literature and clinical guidelines. Implant Dent 2008;17:16-23.

21. Katsuyuki F, Tetsu T, Kensuke Y. Horizontal alveolar ridge augmentation using distraction osteogenesis: comparison with a bone-splitting method in a dog model. Oral Surg Oral Med 0 2009;107:350-8.

22. Basa S, Varol A, Turker N. Alternative bone expansion technique for immediate placement of implants in the edentulous posterior mandibular ridge: a clinical report. Int J Oral Max Impl 2004;19:554-8.

23. Koo S, Dibart S, Weber HP. Ridge-splitting technique with simultaneous implant placement. Compend Contin Educ Dent 2008;29:106-10

24. Demetriades N, Park JI, Laskarides C. Alternative bone expansion technique for implant placement in atrophic edentulous maxilla and mandible. J Oral Implant 2011;37:463-71.

25. Schlee M, Steigmann M, Bratu E, et al. Piezosurgery: basics and possibilities. Implant Dent 2006;15:334-40.

26. Blus C, Szmukler-Moncler S. Split-crest and immediate implant placement with ultra-sonic bone surgery: a 3-year life- 
table analysis with 230 treated sites. Clin Oral Implan Res 2006;17:700-7.

27. Claes L, Augat P, Suger G, et al. Influence of size and stability of the osteotomy gap on the success of fracture healing. $J$ Orthopaed Res 1997;15:577-84.

28. Gómez-Benito MJ, García-Aznar JM, Kuiper JH, et al. Influence of fracture gap size on the pattern of long bone healing: a computational study. J Theor Biol 2005; 235:105-19.

29. Shapiro F. Bone development and its relation to fracture repair. The role of mesenchymal ostoblasts and surface osteoblasts. Eur Cells Mater 2008;15:53-76.

30. Katranji A, Misch K, Wang H-L. Cortical bone thickness in dentate and edentulous human cadavers. J Periodontol 2007;78:
874-8.

31. Swasty D, Lee J, Huang JC, et al. Crosssectional human mandibular morphology as assessed in vivo by cone-beam computed tomography in patients with different vertical facial dimensions. Am J Orthod Dentofac 2011;139:e377-89.

32. Blanco J, Nuñez V, Aracil L, et al. Ridge alterations following immediate implant placement in the dog: flap versus flapless surgery. J Clin Periodontol 2008;35:640-8.

33. Becker W, Goldstein M, Becker BE, et al. Minimally invasive flapless implant surgery: a prospective multicenter study. Clin Implant Dent R 2005;7:21-7.

34. Nkenke E, Eitner S, Radespiel-Tröger M, et al. Patient-centred outcomes comparing transmucosal implant placement with an open approach in the maxilla: a prospective, non-randomized pilot study. Clin Oral Implan Res 2007;18:197-203.

35. Sikes JW, Smith BR, Mukherjee DP. An in vitro study of the effect of bony buttressing on fixation strength of a fractured atrophic edentulous mandible model. J Oral Maxil Surg 2000;58:56-61.

36. Armstrong JEA, Lapointe HJ, V Hogg NJ, et al. Preliminary investigation of the biomechanics of internal fixation of sagittal split osteotomies with miniplates using a newly designed in vitro testing model. $\mathrm{J}$ Oral Maxil Surg 2001;59:191-5.

37. Trivellato AE, Passeri LA. Evaluation of osteotomy fixation changing the number, the extension and the location of the plates. Brit J Oral Max Surg 2006;44:377-81. 